\title{
Ordered $\mathrm{LiNi}_{0.5} \mathrm{Mn}_{1.5} \mathrm{O}_{4}$ Cathode in Bis(fluorosulfonyl)imide-Based Ionic Liquid Electrolyte: Importance of the Cathode-Electrolyte Interphase
}

Hyeon Jeong Lee, ${ }^{\dagger}$ Zachary Brown, $^{\dagger}$ Ying Zhao $^{\ddagger}{ }^{\text {Jack Fawdon }}{ }^{\dagger}$ Weixin Song, $^{\dagger} \mathrm{Ji}$ Hoon Lee, Johannes Ihli, ${ }^{\dagger} \S$ and Mauro Pasta*,†

$\dagger$ Department of Materials, University of Oxford, Oxford OX1 3PH, UK

$\ddagger$ Department of Aerospace Engineering and Applied Mechanics, Tongji University 100 Zhangwu Road, 200092 Shanghai, China

ๆShool of Materials Science and Engineering, Kyungpook National University, 80

Daehak-ro, Buk-gu, Daegu 41566, Republic of Korea

$\S$ Paul Scherrer Institut, 5232 Villigen PSI, Switzerland

E-mail: mauro.pasta@materials.ox.ac.uk

\begin{abstract}
The high voltage $\left(4.7 \mathrm{~V}\right.$ vs. $\left.\mathrm{Li}^{+} / \mathrm{Li}\right)$ spinel lithium nickel manganese oxide $\left(\mathrm{LiNi}_{0.5} \mathrm{Mn}_{1.5} \mathrm{O}_{4}\right.$, LNMO) is a promising candidate for the next-generation of lithium ion batteries due to its high energy density, low cost and environmental impact. However, poor cycling performance at high cutoff potentials limits its commercialization. Herein, hollow structured LNMO is synergistically paired with an ionic liquid electrolyte, $1 \mathrm{M}$ lithium bis(fluorosulfonyl)imide (LiFSI) in N-propyl-N-methylpyrrolidinium bis(fluorosulfonyl)imide
\end{abstract}


$\left(\mathrm{Pyr}_{1,3} \mathrm{FSI}\right)$ to achieve stable cycling performance and improved rate capability. The optimized cathode-electrolyte system exhibits extended cycling performance (>85\% capacity retention after 300 cycles) and high rate performance $\left(106.2 \mathrm{mAh} \mathrm{g}^{-1}\right.$ at $\left.5 \mathrm{C}\right)$ even at an elevated temperature of $65^{\circ} \mathrm{C}$. X-ray photoelectron spectroscopy and spatially resolved x-ray fluorescence analyses confirm the formation of a robust, LiF-rich cathode electrolyte interphase. This study presents a comprehensive design strategy to improve the electrochemical performance of high-voltage cathode materials.

\section{Introduction}

The development of cathode materials that exhibit high energy density, high rate capability, low cost and stable cycling performance is essential to meet the requirements of nextgeneration lithium-ion batteries (LIBs). $\mathrm{LiNi}_{0.5} \mathrm{Mn}_{1.5} \mathrm{O}_{4}(\mathrm{LNMO})$ is one of the potential cathode materials for next-generation LIBs. Its specific capacity of $147 \mathrm{mAh} \mathrm{g}^{-1}$ delivered at an average potential of $4.7 \mathrm{~V}$ vs. $\mathrm{Li}^{+} / \mathrm{Li}$ leads to a theoretical energy density of $\sim 650 \mathrm{~W} \mathrm{~h} \mathrm{~kg}^{-1}$, which is $\sim 15 \%$ lower than the state-of-the-art NMC811 $\left(\sim 760 \mathrm{~W} \mathrm{~h} \mathrm{~kg}^{-1}\right)$ but at $\sim 40 \%$ lower cost, due to its Co free and low Ni composition. ${ }^{1-3}$ Moreover, the three-dimensional diffusion pathways in LNMO's spinel crystal structure results in rapid diffusion of Li-ions and high power density. ${ }^{4,5}$

However, the high working potential of LNMO is a double-edged sword: if on one hand it provides high energy and power density, on the other it means dealing with the instability of carbonate-based organic electrolytes at potentials above $4.5 \mathrm{~V}$ vs. $\mathrm{Li}^{+} / \mathrm{Li}^{6}{ }^{6-9}$ At the high cutoff voltage of $5 \mathrm{~V}$, traditional electrolytes containing organic carbonates and $\mathrm{LiPF}_{6}$ readily decompose to form various by-products such as oxocarbons $\left(\mathrm{CO}\right.$ and $\left.\mathrm{CO}_{2}\right)$ and acidic species, which not only hinder the formation of a stable cathode-electrolyte interphase (CEI) layer, but also cause the dissolution of the transition metals, ultimately leading to poor cycling performance. ${ }^{10-13}$

To mitigate the parasitic reaction between the liquid electrolyte and LNMO surface at 
high cutoff potential, surface coatings of conductive polymers, ${ }^{14-16}$ oxides, ${ }^{17-19}$ and fluorides $^{20-22}$ have proven an effective strategy to improve cyclability and therefore extensively investigated. However, their synthetic complexity effectively undermines the competitive advantage of LNMO's lower bill of materials. Advanced binders and solid polymer electrolytes have also been employed to induce a stable CEI layer on the surface of LNMO, but the uneven coverage of binders and low ionic conductivity of solid polymer electrolytes impede the stability and rate capability of LNMO. ${ }^{23-27}$ Electrolyte solutions using bis(fluorosulfonyl)imide $\left(\mathrm{FSI}^{-}\right)$based ionic liquids show promise thanks to their relatively low viscosity, high chemical and electrochemical stability, and ability to form a robust solid-electrolyte interphase (SEI) that protects the liquid electrolyte from continued decomposition on the surface of the electrode particle. ${ }^{28}$

In this study, we investigate $1 \mathrm{M}$ lithium bis(fluorosulfonyl)imide dissolved in N-propyl-Nmethyl-pyrrolidinium bis(fluorosulfonyl)imide (1M LiFSI in $\mathrm{Pyr}_{1,3} \mathrm{FSI}$ ) as the electrolyte to empower reversible cycling of hollow-structured, ordered LNMO. The composition and morphology of the CEI layer are analysed by means of x-ray photoelectron spectroscopy (XPS) and high-resolution transmission electron microscopy (HR-TEM), respectively highlighting the formation of a uniform and thin $(<8 \mathrm{~nm})$ CEI layer, with composition rich in inorganic fluorides. The robust CEI prevents the side reaction between cathode and electrolyte at high voltages, which is confirmed by spatially resolved x-ray fluorescence (XRF) analysis. Electrochemical impedance spectroscopy (EIS) confirms the formation of a low-resistance CEI that is virtually unaffected by cycling, leading to enhanced coulombic efficiency and prolonged cycle life at both $30{ }^{\circ} \mathrm{C}$ and $65^{\circ} \mathrm{C}$, when compared to a commercial LP30 electrolyte. In addition, we carry out a detailed physicochemical and electrochemical characterisation of the electrolyte to investigate its impact on rate performance. Finally, we hypothesize how a mechanically robust CEI layer coupled with our hollow-structured, spherical secondary particle morphology could function as a capping layer to prevent volume expansion of the particle, thus further improving coulombic efficiency and cycle life. The present study provides a 
useful guideline for designing cathode material-electrolyte systems which attains both stable operation at a high cutoff voltage and enhanced rate capability.

\section{Results and discussion}

Hollow LNMO (H-LNMO) particles were synthesized by a two steps procedure (co-precipitation followed by solid-state reaction) described in detail in the Materials and Methods Section. Synchrotron x-ray diffraction with Rietveld refinement (Figure 1a, Table S1) confirms the synthesis of phase pure LNMO with the cubic $\left(\mathrm{P} 4_{3} 32\right.$ space group) crystal structure $(\mathrm{a}=$ 8.199 A) characteristic of "ordered" LNMO. ${ }^{4,29-32}$
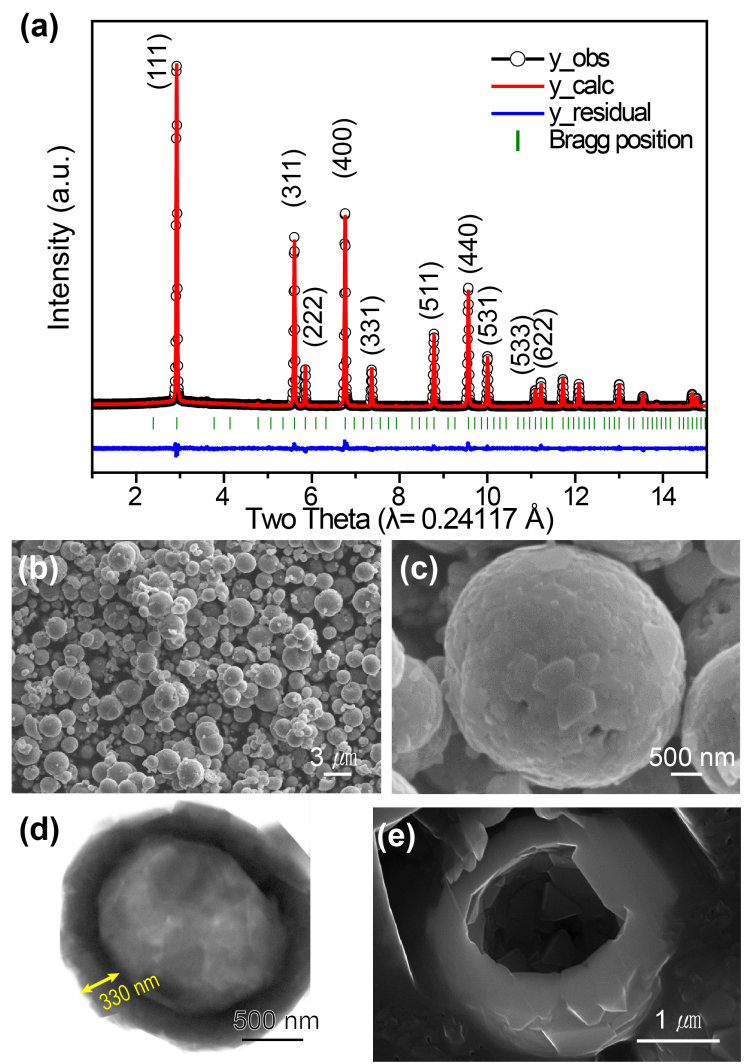

Figure 1. (a) XRD pattern of H-LNMO. The SEM images of H-LNMO at (b) low and (c) high magnification. (d) The high-angle annular dark-field STEM image of H-LNMO. (e) The SEM image of H-LNMO sample using a focused ion beam (FIB)

Scanning electron microscopy (SEM) images show spherical secondary particles 1-3 $\mu \mathrm{m}$ 
(Figure 1b) consisting of platelet-shaped primary particles of about $500 \mathrm{~nm}$, corroborating the average crystallite size of $569 \mathrm{~nm}$ predicted by the Reitveld refinement (Figure 1c, Table S1). Scanning transmission electron microscopy (STEM) image reveals the hollow nature of the particles, with a shell thickness of about $300 \mathrm{~nm}$ (Figure 1d). The hollow structure was confirmed by scanning electron microscopy (SEM) of a focused ion beam (FIB) crosssectioned particle (Figure 1e). Hollow particles are formed because of the difference in diffusion rate between oxygen and transition metals ( $\mathrm{Ni}$ and $\mathrm{Mn}$ ) at the gas-solid interface during synthesis (Kirkendall effect). ${ }^{33,34}$

The electrochemical performance of H-LNMO electrodes prepared as described in the Materials and Methods Section was evaluated in a half cell setup, using lithium metal as reference and counter electrode. The electrolyte we selected was $1 \mathrm{M}$ lithium bis(fluorosulfonyl)imide (LiFSI) dissolved in N-propyl-N-methyl-pyrrolidinium bis(fluorosulfonyl)imide ( $\mathrm{Pyr}_{1,3} \mathrm{FSI}$ ). We will refer to this electrolyte as the room temperature ionic liquid (RTIL) from this point forward. The performance of the RTIL electrolyte was compared with commercial LP30 $\left(1 \mathrm{M} \mathrm{LiPF}{ }_{6}\right.$ in 1:1 EC DMC). $\mathrm{FSI}^{-}$-based ionic liquid (IL) electrolytes have gained popularity in recent years owing to their many favourable properties: namely, low viscosity $(\eta)$, high ionic conductivity $(\chi)$, large electrochemical stability window and the resultant, robust SEI/CEI formed from its decomposition products. ${ }^{35,36}$ As an aliphatic quaternary amide (AQA), $\mathrm{Pyr}_{13}^{+}$-based ILs have proven to show high cathodic stability compared to aromaticbased ILs. Specifically, a 1,3-side chain was chosen because of its favourable melting point, and viscosity at RT. ${ }^{37}$ To balance ionic conductivity, and favourable interfacial kinetics, a $1 \mathrm{M}$ concentration was selected. To understand some of the relevant transport properties of our RTIL, viscosity measurements, and symmetric $\mathrm{Li} / \mathrm{Li}$ cell electrochemical impedance spectroscopy (EIS) measurements were run at $30{ }^{\circ} \mathrm{C}$ and $65{ }^{\circ} \mathrm{C}$. Compared to other IL solutions' viscosities, our RTIL compared favourably, exhibiting viscosities of $63.2 \mathrm{mPa} \cdot \mathrm{s}$ at $30{ }^{\circ} \mathrm{C}$ and $23.2 \mathrm{mPa} \cdot \mathrm{s}$ at $65{ }^{\circ} \mathrm{C}$. Measurements using a symmetric $\mathrm{Li} / \mathrm{Li}$ custom-built cell were run to elucidate information on Li metal-interfacial kinetics and the $\mathrm{Li}^{+}$transference 
(a)
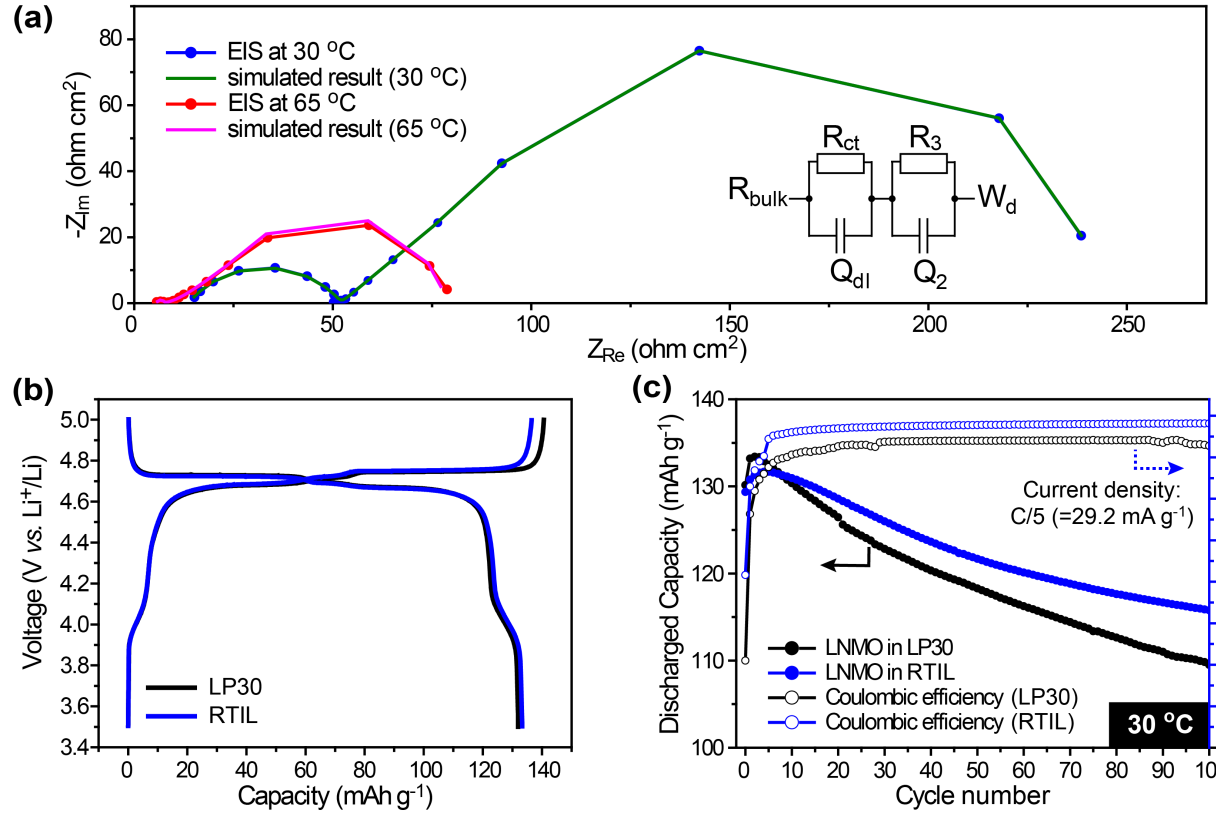

(c)
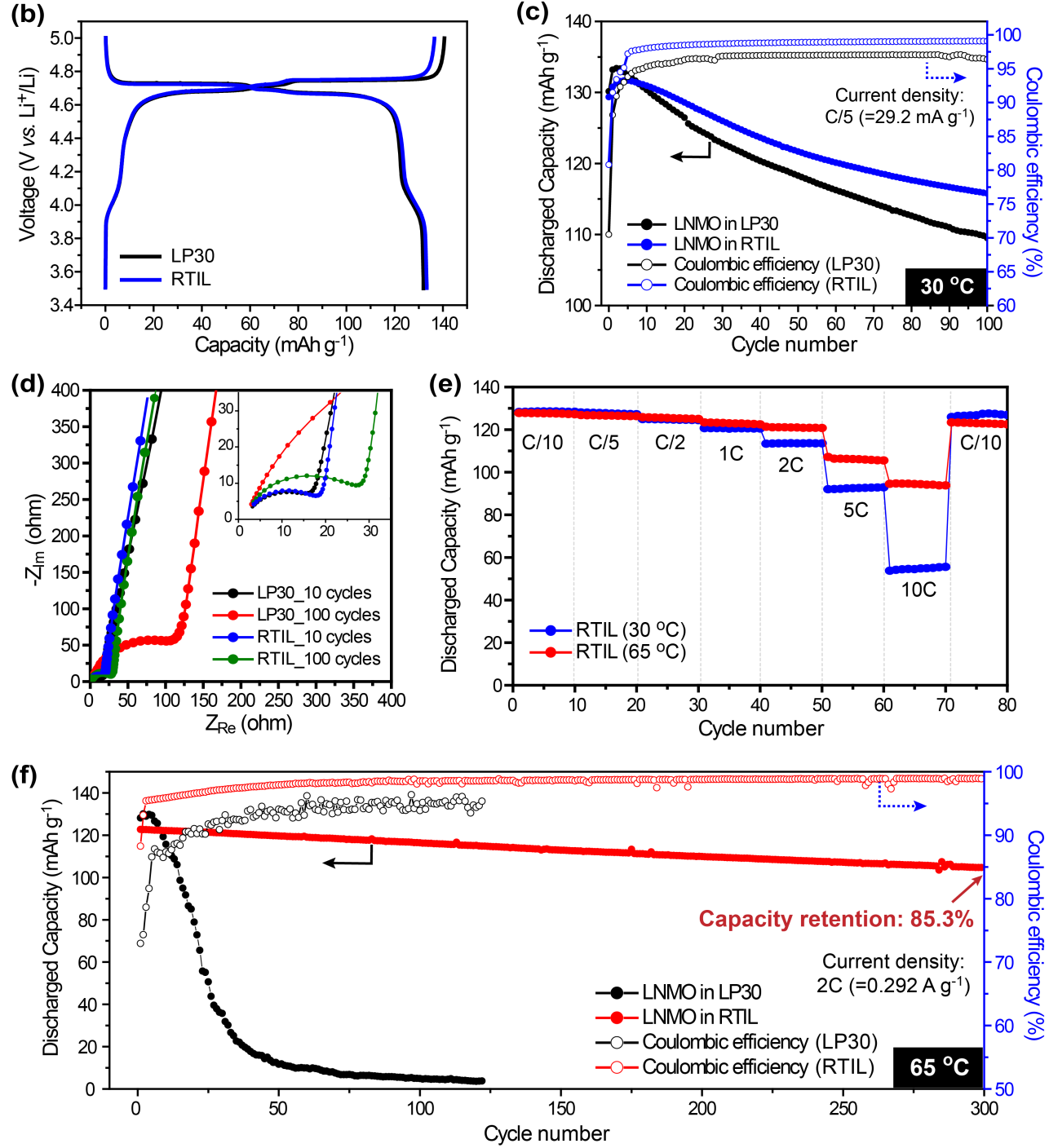

Figure 2. (a) EIS spectra of Li/Li cells with the RTIL at 30 and $65^{\circ} \mathrm{C}$. (b) GCD profiles of H-LNMO in LP30 (black) and RTIL (blue) at C/10. (c) Cycling performance of H-LNMO in LP 30 (black) and RTIL (blue) at C/5. (d) EIS spectra of H-LNMO samples after 10, and 100 cycles in LP 30 and RTIL. (e) The rate performance of H-LNMO in RTIL at different operating temperatures of 30 (blue) and $65{ }^{\circ} \mathrm{C}$ (red). (f) The cyclability of H-LNMO in LP30 (black) and RTIL(red) at the temperature of $65^{\circ} \mathrm{C}$ with the rate of $2 \mathrm{C}$. 
number $\left(t_{\mathrm{Li}^{+}}\right)$. Shorter, medium frequency measurements were first run over $24 \mathrm{~h}$ to confirm the electrolyte's stability against lithium metal. After, a very low frequency measurement was run $(200 \mathrm{kHz}$ to $20 \mathrm{\mu Hz})$ to measure the whole EIS spectrum, including the finite-length Warburg diffusion $\left(\mathrm{W}_{\mathrm{d}}\right)$. This allowed an estimated transference number measurement using the formula $t_{\mathrm{Li}^{+}}=\mathrm{R}_{\text {bulk }} /\left(\mathrm{R}_{\text {bulk }}+\mathrm{W}_{\mathrm{d}}\right) \cdot{ }^{38,39}$ Using the equivalent circuit illustrated in Figure 2a, the spectra were fitted and the properties analysed. At $30^{\circ} \mathrm{C}, \chi$ was calculated to be $3.83 \mathrm{mS} \mathrm{cm}{ }^{-1}$, with a $t_{\mathrm{Li}^{+}}$of 0.076 . And at $65{ }^{\circ} \mathrm{C}$, increased to $10.84 \mathrm{mS} \mathrm{cm}^{-1}$ with a $t_{\mathrm{Li}^{+}}$of 0.078. It is evident that, like all ionic liquid-based electrolytes, $t_{\mathrm{Li}^{+}}$is the limiting property, leading to large concentration gradients across the electrolyte, which is illustrated by the large $\mathrm{W}_{\mathrm{d}}$ resistance. Linear sweep voltammetry (LSV) was performed on LP30 and RTIL to evaluate the electrochemical stability of each electrolyte (Figure S1). The rapid increase of the oxidation current was observed for LP30 at $4.7 \mathrm{~V}$, whereas the RTIL showed a stable electrochemical window up to $5.1 \mathrm{~V}$.

As shown in Figure 2b, both LP30 and RTIL cells exhibited similar discharge capacities of $\sim 132 \mathrm{mAhg}^{-1}$ at $\mathrm{C} / 10$. Three plateaus at $4.8 \mathrm{~V}, 4.7 \mathrm{~V}$ and $4.1 \mathrm{~V}\left(\mathrm{vs} . \mathrm{Li}^{+} / \mathrm{Li}\right.$ ) were observed in galvanostatic charge-discharge (GCD) curve of H-LNMO, which corresponds to the redox voltage plateaus of $\mathrm{Ni}^{4+/ 3+}, \mathrm{Ni}^{3+/ 2+}$ and $\mathrm{Mn}^{4+/ 3+}$, respectively. ${ }^{30,40}$ The very small capacity of $\mathrm{Mn}^{4+/ 3+}$ plateau is indicative of the ordered structure of H-LNMO. Due to the high operating voltage of H-LNMO (4.7 V vs. $\mathrm{Li}^{+} / \mathrm{Li}$ ), the carbonate-based organic electrolyte is unstable, which results in rapid capacity decay. Both cycling performance and coulombic efficiency of the cell cycled with RTIL electrolyte were improved compared to the cell cycled with LP30 electrolyte (Figure 2c). After 100 cycles, the capacity retention of the cell cycled with RTIL electrolyte was $89.5 \%$ of its first cycle capacity, whereas the cell cycled with LP30 electrolyte retained $83.1 \%$ of initial capacity at the same C-rate of C/5. First cycle coulombic efficiency (CE) and average CE of the cell cycled with RTIL electrolyte is $80.8 \%$, and $98.4 \%$, respectively, higher than the cell cycled with LP30 electrolyte (70.5 and 96.2\%, respectively). The lower CE observed for cells cycled with LP30 electrolyte suggests 
the formation of an unstable cathode electrolyte interphase (CEI). ${ }^{41,42}$

The stable cycling performance of the H-LNMO electrode with the RTIL electrolyte is consistent with the EIS measurements of symmetric H-LNMO cells (Figure 2d, Table S2). After 10 cycles, the resistance was quite similar between H-LNMO electrodes cycled with the RTIL and LP30 electrolytes (22.23 vs. $21.94 \Omega$ ). After 100 cycles, the real component of the impedance of the cell cycled with RTIL electrolyte slightly increased to $31.95 \Omega$, whereas the cell cycled with LP30 electrolyte exhibited a significant increase to $148.3 \Omega$. This suggests an unstable CEI is formed on the surface of H-LNMO, continuously reacting with the LP30 electrolyte upon cycling. The rate performance of the H-LNMO electrode was evaluated in the RTIL electrolyte at $30{ }^{\circ} \mathrm{C}$ and $65{ }^{\circ} \mathrm{C}$ (Figure 2e). At $30{ }^{\circ} \mathrm{C}$, the $\mathrm{H}-$ LNMO electrode exhibited the moderate discharge capacities of 92.6 and $54.8 \mathrm{mAh} \mathrm{g}^{-1}$ at high C-rates of 5C and 10C, respectively. Discharge capacities of H-LNMO electrodes were further increased to 106.2 and $94.5 \mathrm{mAh} \mathrm{g}^{-1}$ at the C-rates of $5 \mathrm{C}$ and $10 \mathrm{C}$, respectively, when cycling at $65{ }^{\circ} \mathrm{C}$. High temperatures result in higher diffusivities, which can alleviate the problems associated with low $t_{\mathrm{Li}^{+}}$, namely reducing the extent of the concentration gradient. This could be a primary reason for increased performance of the $65{ }^{\circ} \mathrm{C}$ cell. The cycling performance of H-LNMO cells with LP30 and RTIL electrolytes sharply contrasted at the high operating temperature of $65^{\circ} \mathrm{C}$ (Figure 2f). After 50 cycles, the H-LNMO cell cycled with LP30 electrolyte almost showed zero capacity, whereas the H-LNMO cell cycled with RTIL electrolyte exhibited $85.3 \%$ retention of initial capacity even after 300 cycles. Rapid capacity decaying of H-LNMO cycled with LP30 at high temperatures is related to the thermal stability of LP30. At a high operating temperature, the $\mathrm{LiPF}_{6}$ salt rapidly decomposes to form the $\mathrm{PF}_{5}$, which not only forms $\mathrm{HF}$ but also activates the ring-opening reaction of the cyclic carbonate, resulting in a continuous side reaction at the surface of LNMO and the decomposition of solvent. ${ }^{43-46}$ The half-cell performance of H-LNMO with RTIL electrolyte is compared to other LNMO cathode-electrolyte pairs in Table S3. ${ }^{14,17,47-50}$

The high CE and impressive capacity retention of the H-LNMO cell cycled with RTIL 


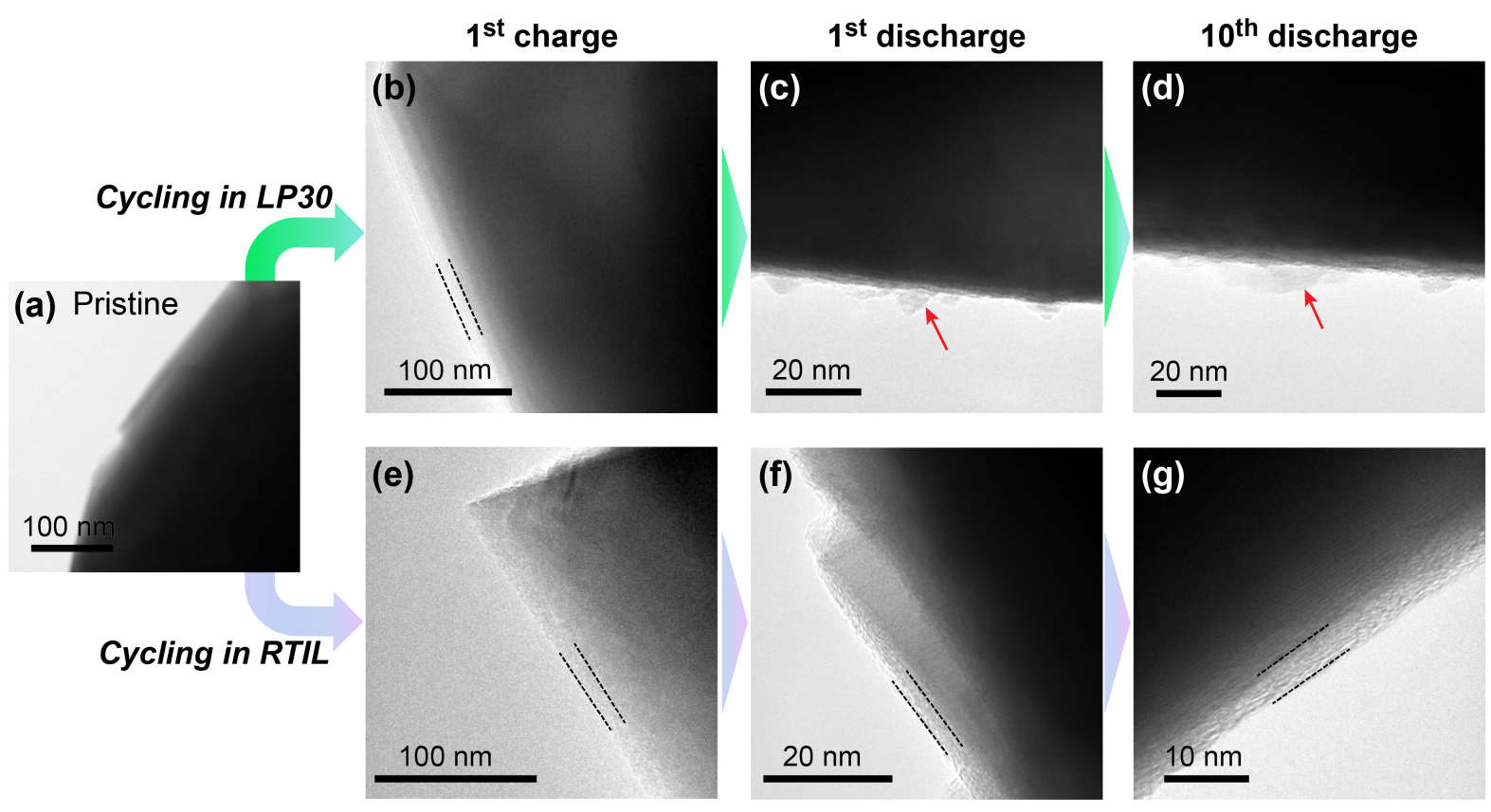

Figure 3. (a) TEM image of pristine H-LNMO , H-LNMO after 1st charge, 1st discharge and after 10 cycles in (b-d) LP30 and (e-g) RTIL at the temperature of $30{ }^{\circ} \mathrm{C}$.

electrolyte are attributed to the formation of a stable CEI on the surface of H-LNMO. Therefore, we extensively assessed the physical and chemical properties of the CEIs formed in both LP30 and RTIL electrolytes. H-LNMO electrodes were harvested after the 1st charge, 1st discharge, and 10 cycles at $30{ }^{\circ} \mathrm{C}$, and imaged ex situ with transmission electron microscopy (TEM) (Figure 3). In the pristine state, the H-LNMO showed a clean surface without an observable layer (Figure 3a). After the 1st charge, amorphous CEI layers with a thickness of less than $8 \mathrm{~nm}$ were formed on the surface of H-LNMO cycled in both LP30 and RTIL electrolytes (Figure 3b,e). A dramatic change in the uniformity of the CEI layer was observed for H-LNMO cycled in LP30 electrolyte after the first discharge process (Figure 3c,f). The CEI layer of H-LNMO cycled with LP30 electrolyte showed an irregular morphology, whereas a uniform film was observed for H-LNMO cycled with RTIL electrolyte. The robust CEI layer of H-LNMO, when cycled with RTIL, is maintained after 100 cycles, thus preventing the side reaction between electrolyte and H-LNMO, which also supports the low impedance of H-LNMO cycled with RTIL after 100 cycles (Figure S2, Figure 2d). The TEM 
observations suggest the CEI layer of H-LNMO cycled with LP30 electrolyte decomposed, thereby exposing pristine cathode material. This pristine surface catalyses further electrolyte decomposition, causing low CE and rapid capacity decay. ${ }^{41,51,52}$
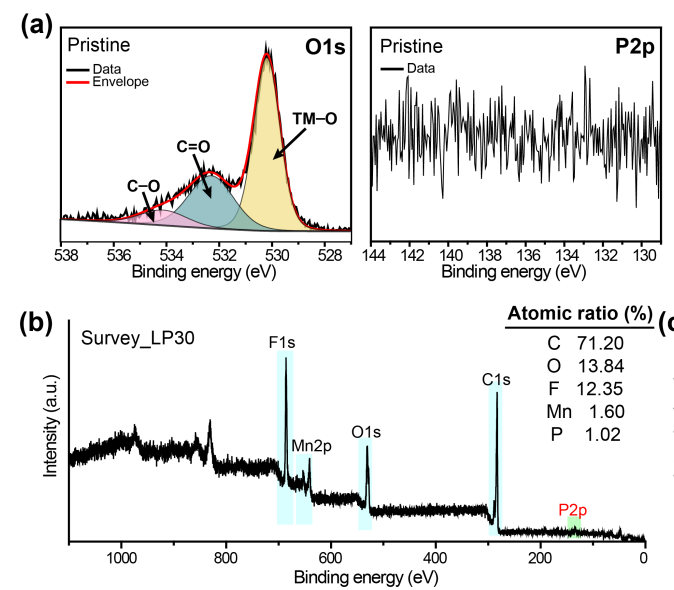

(d)

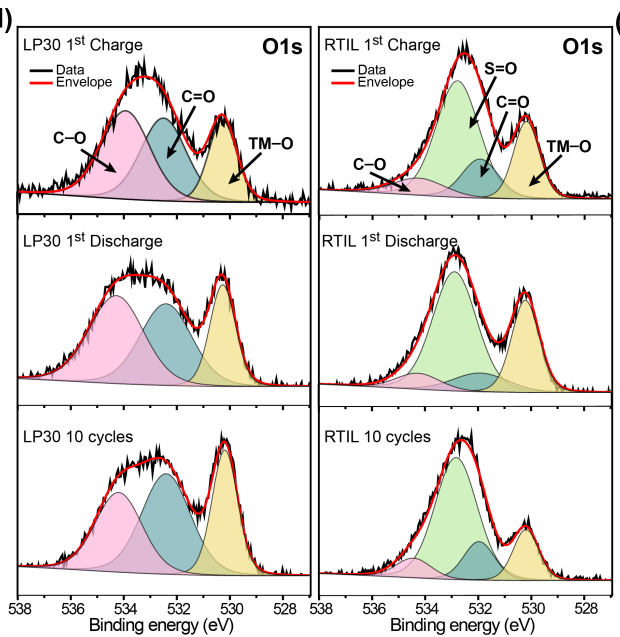

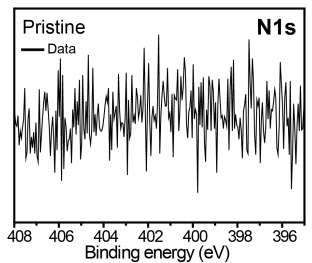
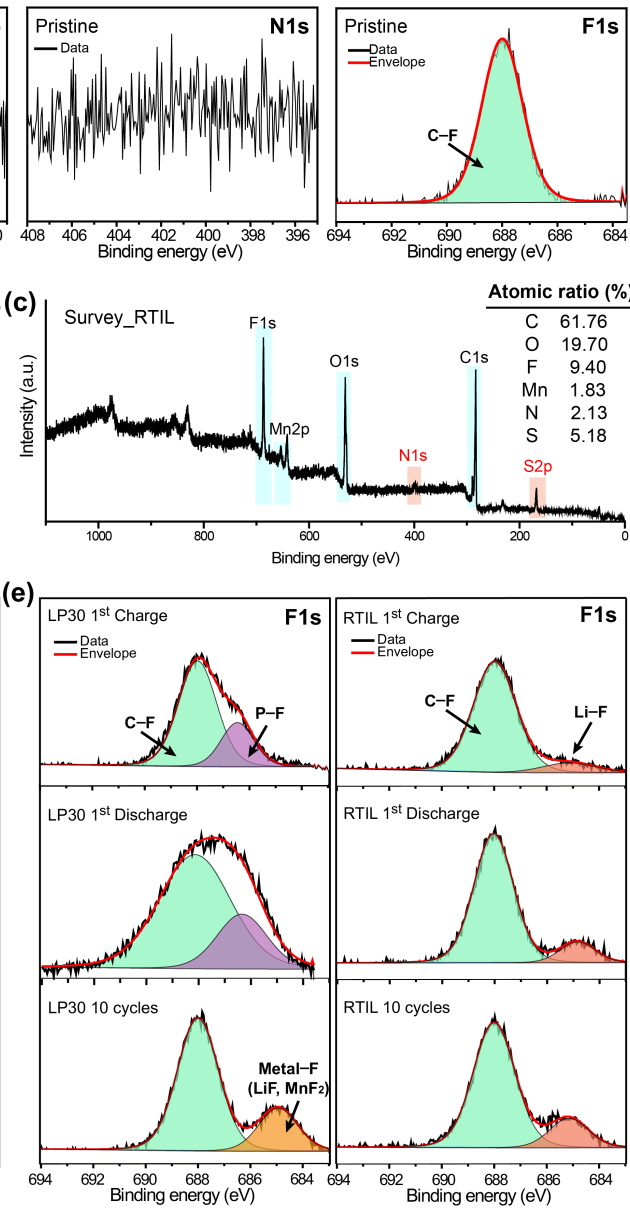

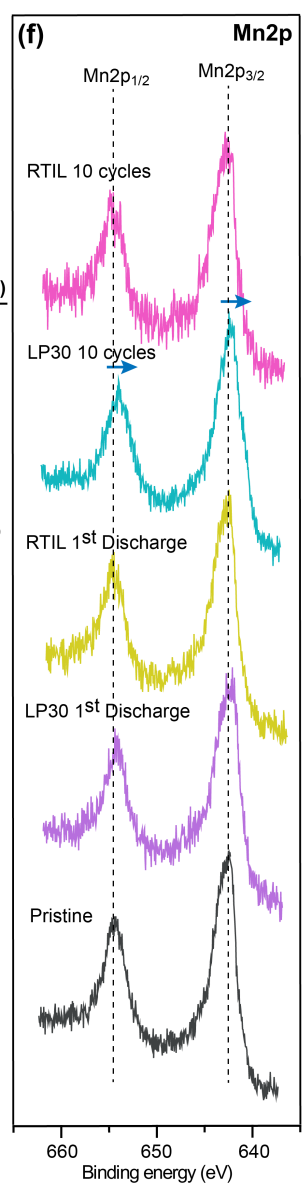

Figure 4. (a) XPS spectra of pristine H-LNMO at O1s, P2p, N1s, and F1s. Survey spectra of H-LNMO which is cycled in LP30 (b) and RTIL (c). Ex situ XPS spectra of H-LNMO in LP30 and RTIL after 1st charge, 1st discharge and 10 cycles at the binding energy regions of O1s (d), 1s (e) and Mn2p (f).

X-ray photoelectron spectroscopy (XPS) measurements were performed to investigate the composition of the CEI formed on the surface of H-LNMO electrodes cycled with LP30 and RTIL electrolytes (Figure 4, Figure S3-S5). The O1s spectrum of the pristine H-LNMO electrode indicates that most of the signal comes from the bond between transition metals (TM) and oxygen in H-LNMO (Figure 4a). A small amount of carbon component peaks was also observed, indicating the formation of carbonate species on the surface of H-LNMO, 
likely from the reaction between H-LNMO and $\mathrm{CO}_{2}$ in the air atmosphere. ${ }^{53,54}$ No peaks were observed in P2p and N1s spectra of the pristine H-LNMO electrode, eliminating the possibility of impurities overlapping with electrolyte-derived CEI products (Figure 4a, Figure S3). Similarly, the F 1s XPS spectrum of the pristine H-LNMO electrode exhibits only C-F bond at $687.98 \mathrm{eV}$ originating from the poly(vinylidene difluoride) (PVDF) binder (Figure 4a). ${ }^{55,56}$

The survey spectra of H-LNMO electrodes after the 1st charge demonstrate how the CEI formed on the surface of H-LNMO differ in composition for each electrolyte. Phosphoruscontaining decomposition products are observed at $\sim 135 \mathrm{eV}$ in the survey spectrum of the H-LNMO electrode cycled with LP30 electrolyte (Figure 4b). For the H-LNMO cell cycled with RTIL electrolyte, the peaks of sulfur and nitrogen were formed at $\sim 170 \mathrm{eV}$ and $\sim 400 \mathrm{eV}$, respectively (Figure 4c), indicating the electrolyte participates in the formation of the CEI layer. After the 1st charge of the H-LNMO cell with LP30 electrolyte, $\mathrm{C}-\mathrm{O}$ and $\mathrm{C}=\mathrm{O}$ are observed as dominating species in the O1s spectrum indicating that the carbonate solvent was decomposed during the charging process, participating in CEI formation (Figure 4d). ${ }^{57-59}$ Further, the C1s spectrum supports the observation of solvent decomposition occurring in LP30 electrolyte, with a significant increase of $\mathrm{C}-\mathrm{O}$ and $\mathrm{C}=\mathrm{O}$ observed on the H-LNMO electrode after the 1st charge of the H-LNMO cell with the LP30 electrolyte (Figure S4).

For the H-LNMO cell cycled with RTIL electrolyte, the ratio of carbon-oxygen component did not increase for the H-LNMO electrode compared to that of the pristine H-LNMO electrode (Figure 4d, Figure S5). Instead of carbon-related species, a significant amount of $\mathrm{SO}_{2}$ moiety $(532.9 \mathrm{eV})$ is present in the O1s spectra, derived from the decomposition of $\mathrm{FSI}^{-}$ anion (Figure 4d). ${ }^{52,60}$ The S2p spectrum of the H-LNMO electrode after the 1st charge also supports the observation of $\mathrm{SO}_{2}$ at 169.3 and $170.5 \mathrm{eV}$ for $2 \mathrm{p}_{3 / 2}$ and $2 \mathrm{p}_{1 / 2}$, respectively (Figure S5). ${ }^{61,62}$ The $\mathrm{SO}_{2}$ moiety is considered to be an effective functional group to improve surface stability of cathodes because it only allows $\mathrm{Li}^{+}$migration by partial negative charge of oxygen atoms while inhibiting the electron transfer at the interface between the electrode 
and the electrolyte, thus suppressing electrolyte decomposition during cycling. ${ }^{63,64}$ Also, a peak is observed at $400.1 \mathrm{eV}$ in the N1s spectrum of the H-LNMO electrode after the 1st charge of the H-LNMO cell with RTIL electrolyte, further confirming that the FSI- anion contributes to the formation of the CEI layer (Figure S5). ${ }^{61,64,65}$

The integrated area ratio of the carbon-oxygen bonds and TM-O decreases for the $\mathrm{H}-$ LNMO electrode cycled with LP30 electrolyte, consistent with the exposure of pristine HLNMO surface observed in the ex situ TEM results. Therefore, it is speculated that the vulnerable CEI layer was attacked by byproducts during electrolyte decomposition, degrading into a non-uniform CEI layer. On the contrary, the integrated area ratio between $\mathrm{S}=\mathrm{O}$ and TM-O for the H-LNMO electrode cycled with RTIL electrolyte has relatively minor change, suggesting a stable CEI was formed (Figure 4d). The F1s XPS spectra directly show the variation in composition of the CEI on the surface of the H-LNMO electrode cycled with LP30 and RTIL electrolytes (Figure 4e). Regarding the 1st charge of the H-LNMO cell with LP30 electrolyte, two peaks at $687.98 \mathrm{eV}$ and $686.45 \mathrm{eV}$ are present in the F1s spectrum of the H-LNMO electrode, attributed to the $\mathrm{C}-\mathrm{F}$ bond and $\mathrm{P}-\mathrm{F}$ bond derived from polyvinylidene difluoride (PVDF) binder and $\mathrm{LiPF}_{6}$ decomposed products, respectively. ${ }^{59,66,67}$ The P2p spectrum supports the observation of $\mathrm{P}-\mathrm{F}$ species, with peaks observed at $136.20 \mathrm{eV}$ and $134.58 \mathrm{eV}$ for $\mathrm{P} 2 \mathrm{p}_{2 / 3}$, corresponding to $\mathrm{Li}_{x} \mathrm{PF}_{y}$ and $\mathrm{Li}_{x} \mathrm{PO}_{y} \mathrm{~F}_{z}$, respectively (Figure $\mathrm{S} 4 \mathrm{~b}$, d, and f). 68,69

The $\mathrm{Li}_{x} \mathrm{PO}_{y} \mathrm{~F}_{z}$ is a degraded product from $\mathrm{LiPF}_{6}$ after 1st charge process based on the following reactions: ${ }^{70,71}$

(1) $\mathrm{PF}_{5}+\mathrm{H}_{2} \mathrm{O} \rightarrow \mathrm{POF}_{3}+2 \mathrm{HF}$

(2) $\mathrm{POF}_{3}+\mathrm{ne}^{-}+\mathrm{nLi}^{+} \rightarrow \mathrm{Li}_{x} \mathrm{PO}_{y} \mathrm{~F}_{z}+\mathrm{LiF}$

However, it is difficult to observe the LiF formation on H-LNMO after the 1st charge of H-LNMO cells with LP30 electrolyte. It is speculated that the hydrofluoric acid (HF), the resultant byproduct in the reaction between the electrolyte and trace water, attacks the CEI layer. After 10 cycles, the new peak arises at $684.93 \mathrm{eV}$, which suggests the sluggish 
formation of inorganic $\mathrm{LiF}$. The formation of $\mathrm{LiF}$ is important as it is a robust $\mathrm{CEI}$ component that can prevent the side reaction between the electrode and electrolyte. ${ }^{20,41,72}$ However, the CEI formed on the surface of H-LNMO in RTIL electrolyte shows stable LiF formation immediately after the 1st charge. Upon cycling, a minor increase in the ratio of LiF and $\mathrm{C}-\mathrm{F}$ is observed, indicating stable CEI formation on the surface of H-LNMO.

The ex situ XPS spectra of Mn2p further suggest the presence of parasitic side reactions between electrolyte and cathode for the H-LNMO cell cycled with LP30 electrolyte (Figure 4f). After the 1st discharge of the H-LNMO cell with LP30 electrolyte, Mn2p peaks of the H-LNMO electrode are slightly shifted to the lower binding energy when compared to peaks in the Mn2p spectrum of the pristine H-LNMO electrode, suggesting the reduction of $\mathrm{Mn}^{4+}$ by HF, at high cutoff voltage. ${ }^{5,12,73}$ The shift of the Mn2p peaks to lower binding energy is severe after 10 cycles, suggesting that the CEI layer formed in LP30 electrolyte is not an effective protective layer of the surface of H-LNMO. In contrast, the peak position in Mn2p spectra does not appear to shift for the H-LNMO electrode cycled with the RTIL electrolyte compared to the pristine H-LNMO electrode. From the XPS analysis, the vulnerable CEI formed on the surface of H-LNMO in LP30 electrolyte cannot prevent the parasitic reactions between electrolyte and cathode interface, leading to continuous dissolution of transition metal. However, the CEI formed on the surface of H-LNMO in RTIL electrolyte is robust during cycling and effectively mitigates the parasitic reaction between the electrolyte and cathode interface, which leads to high $\mathrm{CE}$ and prolonged cycle life.

In order to investigate the stress build-up in the CEI layer and the volume change of the hollow particle upon lithium insertion/deinsertion, a chemo-mechanical model was employed (see Materials and Methods Section). ${ }^{74-76}$ The particle was considered as a two-layered hollow sphere, with the active material as the inner layer with thickness $t$ and the CEI as the outer layer with thickness $t_{o}$.

As shown in Figure 5 and Figure S6, a mechanically robust CEI layer can effectively constrain the volume change of the H-LNMO particle. Although the empty core inevitably 


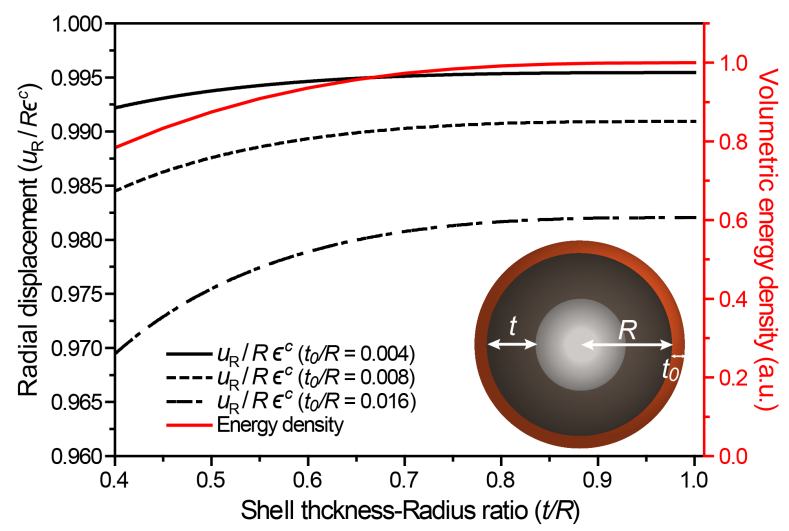

Figure 5. Changes of radial displacement $\left(u_{R} / R \epsilon^{c}\right)$ and volumetric energy density by shell thickness-radius ratio $(t / R)$ at various $t_{o}$ values.

reduces the energy density (red solid line), its presence helps to increase the particle compliance. A CEI layer with a thickness $\left(t_{o}\right)$ of $0.4 \%$ of the particle radius $(R)$ is able to reduce a solid spherical particle expansion by $\sim 0.5 \%$, and the reduction increases to $\sim 1 \%$ for a hollow sphere with a shell thickness of $0.4 R$ (black solid line) (Figure 5). The constraint becomes increasingly significant when the CEI thickness is increased (black dotted and dash-dotted lines). The hoop stress change in the CEI layer by shell thickness-radius ratio also depicts the same tendency. At $t_{o} / R=0.4 \%$ (blue solid line), the hoop stress of the CEI layer decreases by $\sim 0.4 \%$ for a hollow sphere with a shell thickness of $0.4 R$. (Figure S6a). When the Young's modulus of the CEI layer is halved, the hollow structure still contributes to a reduction of both particle volume change and stress in the CEI layer (Figure S6b). The robust microstructure of H-LNMO is verified with ex situ SEM measurement. After 100 cycles, the H-LNMO maintained its original morphology without surface damage originating from transition metal dissolution (Figure S7). ${ }^{18}$ This supports that the accumulated internal stress of the particle originating from the volume change is effectively mitigated due to the hollow structure, resulting in long term cyclability.

The extended cycle life of the H-LNMO electrode in RTIL electrolyte was particularly prominent at the elevated temperature at $65^{\circ} \mathrm{C}$ as shown in Figure 2e. It is speculated that the CEI layer formed on the surface of H-LNMO in RTIL is thermally stable and mitigates 
(a)
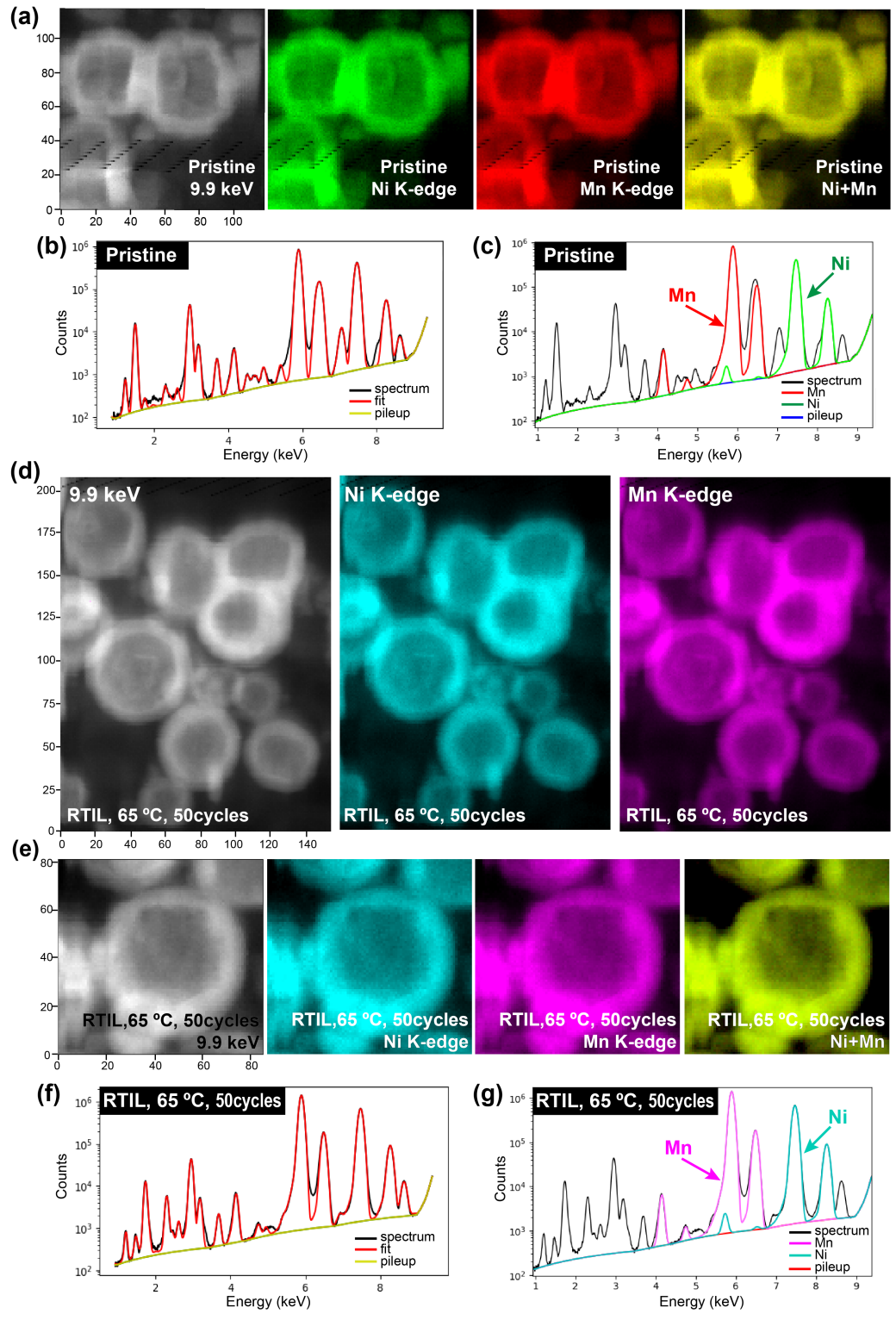

Figure 6. (a) Spatial resolved XRF image of pristine H-LNMO at $9.9 \mathrm{keV}$ and extracted XRF images of H-LNMO at Ni K-edge, Mn K-edge, and combined Ni/Mn K-edge energies. The fitting result of XRF spectrum of pristine H-LNMO and (b) the extracted $\mathrm{Ni}$ and $\mathrm{Mn}$ signals from the measured XRF spectrum (c). (d) Low magnitude-spatial resolved XRF images of H-LNMO after 50 cycles at $65{ }^{\circ} \mathrm{C}$. The collected XRF image at $9.9 \mathrm{keV}$ and extracted XRF images at Ni K-edge, and Mn K-edge energies. (e) Spatial resolved XRF image of single H-LNMO particle after 50 cycles at $65^{\circ} \mathrm{C}$. The collected XRF image at 9.9 $\mathrm{keV}$ and extracted XRF images at Ni K-edge, Mn K-edge, and combined Ni/Mn K-edge energies. (f) The fitting result of XRF spectrum of H-LNMO single particle after 50 cycles at $65{ }^{\circ} \mathrm{C}$ and $(\mathrm{g})$ the extracted $\mathrm{Ni}$ and Mn signals. 
transition metal dissolution even at the high operation temperature. ${ }^{43,77,78}$ Spatially resolved x-ray fluorescence (XRF) analysis was conducted to identify the morphological change and distribution of elements before and after cycling without sample destruction. ${ }^{79-81}$ The spatial resolution of XRF analysis is $50 \mathrm{~nm}$, allowing for effective detection of the transition metal distribution on the particle with high accuracy and reliable qualitative element analysis. At the excitation energy of $9.9 \mathrm{keV}$, the XRF image of pristine H-LNMO shows its hollow structure (Figure 6a). Various elements(Ni, Mn, Al, Fe, Ar, Si, and etc.) were detected within the H-LNMO sample (Figure 6b and Table S4). Most of these elements originated from the sample grid, ion chamber of beam path, and beamline hardware. However, these background signals are not correlated with the H-LNMO (Figure S8).

According to the XRF fitting result, $\mathrm{Ni}$ and $\mathrm{Mn}$ are the only elements which are correlated with the pristine H-LNMO, indicating high sensitivity of the spatial resolved XRF measurement. The $\mathrm{Ni}$ and $\mathrm{Mn}$ are uniformly distributed in the whole particle (Figure 6a), and the atomic ratio between $\mathrm{Ni}$ and $\mathrm{Mn}$ was identified to 1:3.10. The qualitative ratio $\mathrm{Ni} / \mathrm{Mn}$ is calculated by the fluorescence signal of the transition metal at its K-edge (Figure 6c). ${ }^{82}$ After 50 cycles in RTIL at $65{ }^{\circ} \mathrm{C}$, the hollow morphology of H-LNMO is still maintained and exhibits the uniform distribution between $\mathrm{Ni}$ and $\mathrm{Mn}$ around the particle (Figure 6d,e). In addition, a sulfur signal uniformly distributed around the H-LNMO particles can be observed after cycling in RTIL, corroborating the XPS observation of a sulfur-rich CEI (Figure S9 and Table S5). According to fitted values, the atomic ratio between $\mathrm{Ni}$ and $\mathrm{Mn}$ is identified to 1:3.14 (Figure 6f,g), a minor change compared to the $\mathrm{Ni} / \mathrm{Mn}$ ratio of pristine $\mathrm{H}$ LNMO. This observation indicates that the stable CEI layer in RTIL effectively mitigates the transition metal dissolution in a combination of harsh conditions of high operation voltage and high operation temperature. 


\section{Conclusion}

In conclusion, we have demonstrated that stable CEI layer formation in high cutoff voltage significantly improves both cycling performance and CE over a wide temperature range. The FSI $^{-}$anion-based RTIL electrolyte is effective in forming a sulfonyl-based CEI layer which is stable at high cutoff voltage and high operation temperature. In addition, the facile formation of inorganic LiF in CEI layer also prevents both reduction or dissolution of transition metals from the HF attack at the surface of H-LNMO. The hollow secondary particle morphology coupled with robust CEI layer effectively mitigates both volume change and stress level of LNMO induced by lithium insertion and extraction, thus improving structural stability of LNMO and CEI layer, which results in stable cycling performance of H-LNMO. The current study confirms the importance of comprehensive material/electrolyte design for high operating voltage cell and highlights the advancement of LNMO cathode design, important for next generation battery technology.

\section{Materials and Methods}

\section{Synthesis of H-LNMO}

H-LNMO was synthesized by a combination of co-precipitation and solid-state synthesis. All reagents were purchased from Sigma-Aldrich and used without further purification. To obtain the $\mathrm{Ni}_{0.25} \mathrm{Mn}_{0.75} \mathrm{CO}_{3}$ precursor of H-LNMO, $0.249 \mathrm{~g}$ of nickel(II) acetate tetrahydrate $\left(\mathrm{Ni}\left(\mathrm{OCOCH}_{3}\right)_{2} \cdot 4 \mathrm{H}_{2} \mathrm{O}\right)$ and $0.523 \mathrm{~g}$ of manganese(II) sulfate monohydrate $\left(\mathrm{MnSO}_{4} \cdot \mathrm{H}_{2} \mathrm{O}\right)$ were first dissolved in a mixture of $12.5 \mathrm{ml}$ of deionized (DI) water and $6.25 \mathrm{ml}$ of ethanol. After vigorous stirring, $6.5 \mathrm{ml}$ of $0.5 \mathrm{M}$ ammonium bicarbonate $\left(\left(\mathrm{NH}_{4}\right) \mathrm{HCO}_{3}\right)$ and $6 \mathrm{ml}$ of $0.5 \mathrm{M}$ sodium carbonate $\left(\mathrm{Na}_{2} \mathrm{CO}_{3}\right)$ were added to the solution followed by additional stirring for $6 \mathrm{~h}$ at $25^{\circ} \mathrm{C}$. The resulting suspension was transferred to a $100 \mathrm{ml}$ Teflon-lined autoclave reactor, which was sealed and heated at $140{ }^{\circ} \mathrm{C}$ for $10 \mathrm{~h}$. After the reaction was completed, 
the $\mathrm{Ni}_{0.25} \mathrm{Mn}_{0.75} \mathrm{CO}_{3}$ precursor was rinsed with distilled water and ethanol several times and dried at $60{ }^{\circ} \mathrm{C}$ under vacuum for $10 \mathrm{~h}$. Finally, the obtained $\mathrm{Ni}_{0.25} \mathrm{Mn}_{0.75} \mathrm{CO}_{3}$ was mixed with a stoichiometric amount of lithium carbonate $\left(\mathrm{Li}_{2} \mathrm{CO}_{3}\right)$ and heated for $10 \mathrm{~h}$ at $900{ }^{\circ} \mathrm{C}$ in air followed by additional heating at $700{ }^{\circ} \mathrm{C}$ for $4 \mathrm{~h}$.

\section{Characterization}

Crystallographic information was obtained by Reitveld refinement (GSAS-II) of synchrotron X-ray diffraction $(\mathrm{XRD})$ data $(\lambda=0.24117 \AA)$ collected on the 17BM-B beamline at the Advanced Photon Source. The following parameters were refined: (1) scale factor, (2) lattice parameters, (3) position of atoms, and (4) atomic isotropic displacement parameters $\left(\mathrm{U}_{\text {iso }}\right)$. Field emission-scanning electron microscopy (FE-SEM, Zeiss Merlin) and transmission electron microscopy (TEM, JEOL-2100) were employed to probe the morphology of the H-LNMO particles.

\section{Electrochemical Measurement}

H-LNMO electrodes were fabricated by dispersing the active material, super-P (TIMCAL), and poly(vinylidene difluoride) (PVDF, Sigma-Aldrich) in N-methyl-2-pyrrolidinone (NMP, Sigma-Aldrich) with a mass ratio of 8:1:1. To prevent Al corrosion at high potentials, the

slurry was cast onto carbon-coated-Al foil (PI-KEM, UK). The mass loading of the active material was $2.0-2.2 \mathrm{mg} \mathrm{cm}^{-2}$. The room-temperature ionic liquid (RTIL) was prepared by dissolving $3.816 \mathrm{~g}$ of lithium bis(fluorosulfonyl)imide (LiFSI, TCI, 98.0\%) in $20 \mathrm{ml}$ of N-Propyl-N-methylpyrrolidinium bis(fluorosulfonyl)imide ( $\operatorname{Pyr}_{1,3}$ FSI, Solvionic). The LiFSI salt was dried at $80{ }^{\circ} \mathrm{C}$ under vacuum for $12 \mathrm{~h}$ in order to remove traces of $\mathrm{H}_{2} \mathrm{O}$. LP30 (1 M LiPF 6 in EC:DMC(1:1=v:v)) was purchased from Sigma-Aldrich. 2032 coin cells were fabricated in an Ar-filled glovebox in a traditional half-cell configuration with a Li metal foil (Sigma-Aldrich, 99.9\%) acting as both counter and reference electrode. The electrochemical tests were carried out by galvanostatic charge-discharge measurements in the potential range 
3.5-5.0 V (vs. $\mathrm{Li}^{+} / \mathrm{Li}$ ) using a battery cycler (VMP3, Biologic, France) at 30 and $65{ }^{\circ} \mathrm{C}$. The C-rate is defined based on $1 \mathrm{C}=146 \mathrm{mAg}^{-1}$. Electrochemical impedance spectroscopy(EIS) measurements were performed using a frequency response analyzer (VMP3, Biologic, France) over the frequency range of $0.01 \mathrm{~Hz}-1 \mathrm{MHz}$ with a voltage amplitude of $10 \mathrm{mV}$. The EIS characterization was carried out in a custom built cell using a $\mathrm{Li} / \mathrm{Li}$ setup with $350 \mathrm{\mu l}$ of electrolyte, soaked in a Whatman microfiber GF/F separator. The interelectrode distance was $550 \mu \mathrm{m}$, and an area of $2 \mathrm{~cm}$ for each electrode. Using the same analyzer described above, the frequency range used was $200 \mathrm{kHz}-20 \mu \mathrm{Hz}$, with a voltage amplitude of $5 \mathrm{mV}$. This voltage amplitude was deemed optimal to balance resolution and linearity. A highprecision temperature-controlled viscometer was used (Lovis 2000 M microviscometer using a $1.8 \mathrm{~mm}$ diameter capillary and a $1.8 \mathrm{~mm}$ diameter steel ball) to measure the viscosity of the RTIL electrolyte at 30 and $65^{\circ} \mathrm{C}$.

\section{Ex situ XPS and TEM Analyses}

For the sample preparation, electrodes were soaked in dimethly carbonate (DMC) for $24 \mathrm{~h}$ to remove residual electrolyte and salt and subsequently dried under vacuum for $10 \mathrm{~h}$. For ex situ XPS, the electrodes were transferred to the XPS chamber with a vacuum transfer vessels to avoid air exposure. XPS spectra were collected using a Phi XPS VersaProbe III with an $\mathrm{Al} \mathrm{K}_{\alpha} \mathrm{X}$-ray source. Data quantification was performed using CasaXPS software. All spectra were charge-referenced to the disordered C1s component at a binding energy of $284.8 \mathrm{eV}$. For ex situ TEM analysis, the dried electrodes were soaked again in NMP and sonicated for $10 \mathrm{sec}$. To minimize adverse side reaction with the CEI layer, the sample exposure to NMP was strictly minimised to 30 seconds. The supernatant was dropped on the lacey carbon film of a $\mathrm{Cu}$ TEM grid. The TEM grids were dried under vacuum at $60{ }^{\circ} \mathrm{C}$ for $10 \mathrm{~h}$. The CEI layer change was observed by TEM (JEOL ARM-200F) at an acceleration voltage of $200 \mathrm{kV}$. 


\section{Mechanical Modelling}

In the chemo-mechanical model of volume expansion and hoop stress, the compositional variation of $\mathrm{Li}^{+}$ion inside the particle is ignored. In this calculation, $\mathrm{LiF}$ is modeled as a CEI layer. Both LNMO and LiF are considered as isotropic linear elastic materials. Analytical expressions for the radial displacement and hoop stress are obtained based on following equations:

$$
\begin{gathered}
\frac{u_{R}}{R \epsilon^{c}}=\frac{1}{1+\frac{2 \bar{t}_{o}}{1-(1-\bar{t})^{3}}\left[\frac{E_{o}}{E} \frac{1-2 \nu}{1-\nu_{o}}+\frac{E_{o}}{E} \frac{1+\nu}{2\left(1-\nu_{o}\right)}(1-\bar{t})^{3}\right]} \\
\frac{\sigma_{t}}{E \epsilon^{c}}=\frac{1}{\frac{E\left(1-\nu_{o}\right)}{E_{o}}+\frac{2 \bar{t}_{0}(1-2 \nu)}{1-(1-\bar{t})^{3}}+\frac{\bar{t}_{o}(1+\nu)(1-\bar{t})^{3}}{1-(1-\bar{t})^{3}}}
\end{gathered}
$$

$\bar{t}$ and $\overline{t_{o}}$ are the inner and outer shell thicknesses normalized against the particle radius $(R) . E$ and $\nu$ represent Young's modulus and Poisson's ratio of LNMO, respectively. $R_{o}$ and $E_{o}$ refer to the elastic properties of the CEI layer. $\epsilon^{c}$ is the chemical strain due to lithium insertion in LNMO. All the values of elastic properties in this study were extracted from the literature.

\section{Spatial Resolved X-ray Fluorescence (XRF) Analysis}

Spatial resolved XRF measurement was conducted at the I14 beamline at the Diamond Light Source. The H-LNMO samples were prepared from pristine electrode and electrode cycled 50 times in RTIL at $65^{\circ} \mathrm{C}$ by dispersion in ethanol and loading on either an $\mathrm{Al}$ TEM grid or a $\mathrm{Si}_{3} \mathrm{~N}_{4}$ window. The samples were covered by epoxy resin to prevent air exposure during the measurement. The whole process of sample preparation was conducted in an Ar-filled glovebox. A monochromatic beam of $9.9 \mathrm{keV}$ was selected as an excitation energy for spatial resolved XRF analysis. The spatial resolution of each pixel was $50 \mathrm{~nm}$. The obtained ROI (Region of Interest) image processing and data quantification were performed by using PyMca software. The Rayleigh scattering peak of XRF spectrum was calibrated to the excitation energy of $9.9 \mathrm{keV}$. The resultant mass fraction is converted to atomic ratio 
based on the atomic weight of $\mathrm{Ni}$ and $\mathrm{Mn}$.

\section{Notes}

The authors declare no competing interests.

\section{Acknowledgement}

The authors would like to acknowledge the the ISCF Faraday Challenge project SOLBAT [grant number FIRG007] and the Henry Royce Institute (through UK Engineering and Physical Science Research Council grant EP/R010145/1) for capital equipment. We acknowledge technical supports with I14 beamline at Diamond Light Source under Proposal MG22264, and 17-BM-B beamline at Advanced Photon Source (APS, Contract No. DEAC02-06CH11357). H. J. Lee acknowledges support from the National Research Foundation of Korea (NRF-2019R1A6A3A03031343). Y.Z. is supported by Shanghai Sailing Program (Project No. 20YF1452300) and the Fundamental Research Funds for the Central Universities. We are grateful to the David Cockayne Center for Electron Microscopy for the use of their electron microscopes.

\section{Supporting Information Available}

The Supporting Information is available free of charge at https://pubs.acs.org/XXXXXXXXXX

LSV curves of electrolytes, ex situ TEM/SEM images, additional xps spectra of H-LNMO, Hoop stress of CEI layer, and spatial resolved XRF data of H-LNMO

\section{References}

(1) Wentker, M.; Greenwood, M.; Leker, J. A Bottom-Up Approach to Lithium-Ion Battery Cost Modeling with a Focus on Cathode Active Materials. Energies 2019, 12, 504. 
(2) Li, W.; Cho, Y. G.; Yao, W.; Li, Y.; Cronk, A.; Shimizu, R.; Schroeder, M. A.; Fu, Y.; Zou, F.; Battaglia, V.; Manthiram, A.; Zhang, M.; Meng, Y. S. Enabling high areal capacity for Co-free high voltage spinel materials in next-generation Li-ion batteries. Journal of Power Sources 2020, 473, 228579.

(3) Liang, G.; Peterson, V. K.; See, K. W.; Guo, Z.; Pang, W. K. Developing high-voltage spinel LiNi 0.5 Mn 1.5 O 4 cathodes for high-energy-density lithium-ion batteries: current achievements and future prospects . Journal of Materials Chemistry A 2020, 8, $15373-15398$.

(4) Manthiram, A.; Chemelewski, K.; Lee, E. S. A perspective on the high-voltage LiMn1.5Ni0.5O 4 spinel cathode for lithium-ion batteries. Energy and Environmental Science 2014, 7, 1339-1350.

(5) Ma, J.; Hu, P.; Cui, G.; Chen, L. Surface and Interface Issues in Spinel LiNi0.5Mn1.5O4: Insights into a Potential Cathode Material for High Energy Density Lithium Ion Batteries. Chemistry of Materials 2016, 28, 3578-3606.

(6) Leung, K. First-principles modeling of the initial stages of organic solvent decomposition on Li xMn $2 \mathrm{O}$ 4(100) surfaces. Journal of Physical Chemistry C 2012, 116, 9852-9861.

(7) Demeaux, J.; Lemordant, D.; Caillon-Caravanier, M.; Galiano, H.; Claude-Montigny, B. New insights into a high potential spinel and alkylcarbonate-based electrolytes. Electrochimica Acta 2013, 89, 163-172.

(8) Zou, Z.; Xu, H.; Zhang, H.; Tang, Y.; Cui, G. Electrolyte Therapy for Improving the Performance of LiNi0.5Mn1.5O4 Cathodes Assembled Lithium-Ion Batteries. ACS Applied Materials and Interfaces 2020, 12, 21368-21385.

(9) Jung, R.; Metzger, M.; Maglia, F.; Stinner, C.; Gasteiger, H. A. Chemical versus electrochemical electrolyte oxidation on NMC111, NMC622, NMC811, LNMO, and conductive carbon. Journal of Physical Chemistry Letters 2017, 8, 4820-4825. 
(10) Han, J. G.; Kim, K.; Lee, Y.; Choi, N. S. Scavenging Materials to Stabilize LiPF 6 -Containing Carbonate-Based Electrolytes for Li-Ion Batteries. Advanced Materials 2019, 31, 1804822.

(11) Xu, M.; Tsiouvaras, N.; Garsuch, A.; Gasteiger, H. A.; Lucht, B. L. Generation of cathode passivation films via oxidation of lithium bis(oxalato) borate on high voltage spinel (LiNi0.5Mn 1.5O4). Journal of Physical Chemistry C 2014, 118, 7363-7368.

(12) Pieczonka, N. P.; Yang, L.; Balogh, M. P.; Powell, B. R.; Chemelewski, K.; Manthiram, A.; Krachkovskiy, S. A.; Goward, G. R.; Liu, M.; Kim, J. H. Impact of lithium bis(oxalate)borate electrolyte additive on the performance of high-voltage spinel/graphite Li-ion batteries. Journal of Physical Chemistry C 2013, 117, 2260322612 .

(13) Jarry, A.; Gottis, S.; Yu, Y. S.; Roque-Rosell, J.; Kim, C.; Cabana, J.; Kerr, J.; Kostecki, R. The Formation Mechanism of Fluorescent Metal Complexes at the LixNi0.5Mn1.5O4- $\delta /$ Carbonate Ester Electrolyte Interface. Journal of the American Chemical Society 2015, 137, 3533-3539.

(14) Dong, H.; Zhang, Y.; Zhang, S.; Tang, P.; Xiao, X.; Ma, M.; Zhang, H.; Yin, Y.; Wang, D.; Yang, S. Improved High Temperature Performance of a Spinel LiNi0.5Mn1.5O4 Cathode for High-Voltage Lithium-Ion Batteries by Surface Modification of a Flexible Conductive Nanolayer. ACS Omega 2019, 4, 185-194.

(15) Kwon, Y.; Lee, Y.; Kim, S. O.; Kim, H. S.; Kim, K. J.; Byun, D.; Choi, W. Conducting Polymer Coating on a High-Voltage Cathode Based on Soft Chemistry Approach toward Improving Battery Performance. ACS Applied Materials and Interfaces 2018, 10, 29457-29466.

(16) Gao, X. W.; Deng, Y. F.; Wexler, D.; Chen, G. H.; Chou, S. L.; Liu, H. K.; Shi, Z. C.; Wang, J. Z. Improving the electrochemical performance of the LiNi0.5Mn1.5O4 spinel 
by polypyrrole coating as a cathode material for the lithium-ion battery. Journal of Materials Chemistry A 2015, 3, 404-411.

(17) Kim, J. W.; Kim, D. H.; Oh, D. Y.; Lee, H.; Kim, J. H.; Lee, J. H.; Jung, Y. S. Surface chemistry of LiNi0.5Mn1.5O4 particles coated by $\mathrm{Al} 2 \mathrm{O} 3$ using atomic layer deposition for lithium-ion batteries. Journal of Power Sources 2015, 274, 1254-1262.

(18) Zhao, R.; Li, L.; Xu, T.; Wang, D.; Pan, D.; He, G.; Zhao, H.; Bai, Y. One-Step Integrated Surface Modification to Build a Stable Interface on High-Voltage Cathode for Lithium-Ion Batteries. ACS Applied Materials and Interfaces 2019, 11, 1623316242.

(19) Chong, J.; Xun, S.; Song, X.; Liu, G.; Battaglia, V. S. Surface stabilized LiNi0.5Mn1.5O4 cathode materials with high-rate capability and long cycle life for lithium ion batteries. Nano Energy 2013, 2, 283-293.

(20) Tiurin, O.; Solomatin, N.; Auinat, M.; Ein-Eli, Y. Atomic layer deposition (ALD) of lithium fluoride $(\mathrm{LiF})$ protective film on Li-ion battery LiMn1.5Ni0.5O4 cathode powder material. Journal of Power Sources 2020, 448, 227373.

(21) Chu, C. T.; Mondal, A.; Kosova, N. V.; Lin, J. Y. Improved high-temperature cyclability of AlF3 modified spinel LiNi0.5Mn1.5O4 cathode for lithium-ion batteries. Applied Surface Science 2020, 530, 147169.

(22) Li, Y.; Zhang, Q.; Xu, T.; Wang, D.; Pan, D.; Zhao, H.; Bai, Y. LaF3 nanolayer surface modified spinel LiNi0.5Mn1.5O4 cathode material for advanced lithium-ion batteries. Ceramics International 2018, 44, 4058-4066.

(23) Ma, Y.; Chen, K.; Ma, J.; Xu, G.; Dong, S.; Chen, B.; Li, J.; Chen, Z.; Zhou, X.; Cui, G. A biomass based free radical scavenger binder endowing a compatible cathode interface for $5 \mathrm{v}$ lithium-ion batteries. Energy and Environmental Science 2019, 12, 273-280. 
(24) Pieczonka, N. P.; Borgel, V.; Ziv, B.; Leifer, N.; Dargel, V.; Aurbach, D.; Kim, J. H.; Liu, Z.; Huang, X.; Krachkovskiy, S. A.; Goward, G. R.; Halalay, I.; Powell, B. R.; Manthiram, A. Lithium Polyacrylate (LiPAA) as an Advanced Binder and a Passivating Agent for High-Voltage Li-Ion Batteries. Advanced Energy Materials 2015, 5, 1501008.

(25) Xu, H.; Zhang, H.; Ma, J.; Xu, G.; Dong, T.; Chen, J.; Cui, G. Overcoming the Challenges of 5 v Spinel LiNi0.5Mn1.5O4 Cathodes with Solid Polymer Electrolytes. ACS Energy Letters 2019, 4, 2871-2886.

(26) Zhang, H.; Zhang, J.; Ma, J.; Xu, G.; Dong, T.; Cui, G. Polymer Electrolytes for High Energy Density Ternary Cathode Material-Based Lithium Batteries. Electrochemical Energy Reviews 2019, 2, 128-148.

(27) Dong, T.; Zhang, H.; Ma, Y.; Zhang, J.; Du, X.; Lu, C.; Shangguan, X.; Li, J.; Zhang, M.; Yang, J.; Zhou, X.; Cui, G. A well-designed water-soluble binder enlightening the $5 \mathrm{~V}$-class LiNi0.5Mn1.5O4 cathodes. Journal of Materials Chemistry A 2019, 7, 24594-24601.

(28) Shkrob, I. A.; Marin, T. W.; Zhu, Y.; Abraham, D. P. Why Bis(fluorosulfonyl)imide is a "Magic Anion" for Electrochemistry? Journal of Physical Chemistry C 2014, 118, 19661-19671.

(29) Aktekin, B.; Massel, F.; Ahmadi, M.; Valvo, M.; Hahlin, M.; Zipprich, W.; Marzano, F.; Duda, L.; Younesi, R.; Edström, K.; Brandell, D. How Mn/Ni Ordering Controls Electrochemical Performance in High-Voltage Spinel LiNi0.44Mn1.56O4with Fixed Oxygen Content. ACS Applied Energy Materials 2020, 3, 6001-6013.

(30) Yang, J.; Han, X.; Zhang, X.; Cheng, F.; Chen, J. Spinel LiNi0.5Mn1.5O4 cathode for rechargeable lithiumion batteries: Nano vs micro, ordered phase (P4332) vs disordered phase (Fd3m). Nano Research 2013, 6, 679-687. 
(31) Liu, D.; Zhu, W.; Trottier, J.; Gagnon, C.; Barray, F.; Guerfi, A.; Mauger, A.; Groult, H.; Julien, C. M.; Goodenough, J. B.; Zaghib, K. Spinel materials for highvoltage cathodes in Li-ion batteries. $R S C$ Advances 2014, 4, 154-167.

(32) Toby, B. H.; Von Dreele, R. B. GSAS-II: The genesis of a modern open-source all purpose crystallography software package. Journal of Applied Crystallography 2013, $46,544-549$.

(33) Yin, Y.; Rioux, R. M.; Erdonmez, C. K.; Hughes, S.; Somorjal, G. A.; Alivisatos, A. P. Formation of Hollow Nanocrystals Through the Nanoscale Kirkendall Effect. Science 2004, 304, 711-714.

(34) Li, S.; Geng, S.; Zhao, J.; Cui, X. Synthesis of LiNi0.5Mn1.5O4 nano/microspheres with adjustable hollow structures for lithium-ion battery. Ionics 2018, 24, 681-688.

(35) Best, A. S.; Bhatt, A. I.; Hollenkamp, A. F. Ionic Liquids with the Bis(fluorosulfonyl)imide Anion: Electrochemical Properties and Applications in Battery Technology. Journal of The Electrochemical Society 2010, 15\%, A903.

(36) Kerner, M.; Johansson, P. Pyrrolidinium fsi and TFSI-based polymerized ionic liquids as electrolytes for high-temperature lithium-ion batteries. Batteries 2018, 4, 10.

(37) Matsumoto, H.; Sakaebe, H.; Tatsumi, K. Preparation of room temperature ionic liquids based on aliphatic onium cations and asymmetric amide anions and their electrochemical properties as a lithium battery electrolyte. Journal of Power Sources 2005, 146, $45-50$.

(38) Wohde, F.; Balabajew, M.; Roling, B. Li + Transference Numbers in Liquid Electrolytes Obtained by Very-Low-Frequency Impedance Spectroscopy at Variable Electrode Distances . Journal of The Electrochemical Society 2016, 163, A714-A721. 
(39) Sälzer, F.; Pateras Pescara, L.; Franke, F.; Müller, C.; Winkler, J.; Schwalm, M.; Roling, B. Assessing the Ion Transport Properties of Highly Concentrated Non-Flammable Electrolytes in a Commercial Li-Ion Battery Cell. Batteries \& Supercaps 2020, 3, 117125.

(40) Kim, J. H.; Huq, A.; Chi, M.; Pieczonka, N. P.; Lee, E.; Bridges, C. A.; Tessema, M. M.; Manthiram, A.; Persson, K. A.; Powell, B. R. Integrated nano-domains of disordered and ordered spinel phases in LiNi0.5Mn1.5O4 for li-ion batteries. Chemistry of Materials 2014, 26, 4377-4386.

(41) Liu, W.; Li, J.; Li, W.; Xu, H.; Zhang, C.; Qiu, X. Inhibition of transition metals dissolution in cobalt-free cathode with ultrathin robust interphase in concentrated electrolyte. Nature Communications 2020, 11, 3629.

(42) Kasnatscheew, J.; Evertz, M.; Streipert, B.; Wagner, R.; Klöpsch, R.; Vortmann, B.; Hahn, H.; Nowak, S.; Amereller, M.; Gentschev, A. C.; Lamp, P.; Winter, M. The truth about the 1st cycle Coulombic efficiency of LiNi1/3Co1/3Mn1/3O2 (NCM) cathodes. Physical Chemistry Chemical Physics 2016, 18, 3956-3965.

(43) Cao, X.; He, X.; Wang, J.; Liu, H.; Röser, S.; Rad, B. R.; Evertz, M.; Streipert, B.; Li, J.; Wagner, R.; Winter, M.; Cekic-Laskovic, I. High Voltage LiNi0.5Mn1.5O4/Li4Ti5O12 Lithium Ion Cells at Elevated Temperatures: Carbonateversus Ionic Liquid-Based Electrolytes. ACS Applied Materials and Interfaces 2016, 8, $25971-25978$.

(44) Weber, W.; Wagner, R.; Streipert, B.; Kraft, V.; Winter, M.; Nowak, S. Ion and gas chromatography mass spectrometry investigations of organophosphates in lithium ion battery electrolytes by electrochemical aging at elevated cathode potentials. Journal of Power Sources 2016, 306, 193-199.

(45) He, M.; Boulet-Roblin, L.; Borel, P.; Tessier, C.; Novák, P.; Villevieille, C.; Berg, E. J. 
Effects of Solvent, Lithium Salt, and Temperature on Stability of Carbonate-Based Electrolytes for 5.0 V LiNi 0.5 Mn 1.5 O 4 Electrodes. Journal of The Electrochemical Society 2016, 163, A83-A89.

(46) Tebbe, J. L.; Fuerst, T. F.; Musgrave, C. B. Degradation of Ethylene Carbonate Electrolytes of Lithium Ion Batteries via Ring Opening Activated by LiCoO2 Cathode Surfaces and Electrolyte Species. ACS Applied Materials and Interfaces 2016, 8, 2666426674 .

(47) Pan, J. J.; Chen, B.; Xie, Y.; Ren, N.; Yi, T. F. V2O5 modified LiNi0.5Mn1.5O4 as cathode material for high-performance Li-ion battery. Materials Letters 2019, 253, 136-139.

(48) Liang, F.; Yu, J.; Chen, J.; Wang, D.; Lin, C.; Zhu, C.; Wang, M.; Dong, L.; Li, C. A novel boron-based ionic liquid electrolyte for high voltage lithium-ion batteries with outstanding cycling stability. Electrochimica Acta 2018, 283, 111-120.

(49) Wu, C. J.; Rath, P. C.; Patra, J.; Bresser, D.; Passerini, S.; Umesh, B.; Dong, Q. F.; Lee, T. C.; Chang, J. K. Composition Modulation of Ionic Liquid Hybrid Electrolyte for 5 v Lithium-Ion Batteries. ACS Applied Materials and Interfaces 2019, 11, 4204942056.

(50) Qi, H.; Ren, Y.; Guo, S.; Wang, Y.; Li, S.; Hu, Y.; Yan, F. High-Voltage Resistant Ionic Liquids for Lithium-Ion Batteries. ACS Applied Materials and Interfaces 2020, 12, 591-600.

(51) Intan, N. N.; Klyukin, K.; Alexandrov, V. Ab Initio Modeling of Transition Metal Dissolution from the LiNi0.5Mn1.5O4 Cathode. ACS Applied Materials and Interfaces 2019, 11, 20110-20116.

(52) Alvarado, J.; Schroeder, M. A.; Zhang, M.; Borodin, O.; Gobrogge, E.; Olguin, M.; 
Ding, M. S.; Gobet, M.; Greenbaum, S.; Meng, Y. S.; Xu, K. A carbonate-free, sulfonebased electrolyte for high-voltage Li-ion batteries. Materials Today 2018, 21, 341-353.

(53) Kim, J.; Hong, Y.; Ryu, K. S.; Kim, M. G.; Cho, J. Washing effect of a LiNi0.83Co0.15Al $0.02 \mathrm{O} 2$ cathode in water. Electrochemical and Solid-State Letters 2006, 9, A19-A23.

(54) Zhuang, G. V.; Chen, G.; Shim, J.; Song, X.; Ross, P. N.; Richardson, T. J. Li2CO3 in $\mathrm{LiNi} 0.8 \mathrm{Co} 0.15 \mathrm{Al} 0.05 \mathrm{O} 2$ cathodes and its effects on capacity and power. Journal of Power Sources 2004, 134, 293-297.

(55) Jiao, S. et al. Stable cycling of high-voltage lithium metal batteries in ether electrolytes. Nature Energy 2018, 3, 739-746.

(56) Cherkashinin, G.; Nikolowski, K.; Ehrenberg, H.; Jacke, S.; Dimesso, L.; Jaegermann, W. The stability of the SEI layer, surface composition and the oxidation state of transition metals at the electrolyte-cathode interface impacted by the electrochemical cycling: X-ray photoelectron spectroscopy investigation. Physical Chemistry Chemical Physics 2012, 14, 12321-12331.

(57) Qian, Y.; Schultz, C.; Niehoff, P.; Schwieters, T.; Nowak, S.; Schappacher, F. M.; Winter, M. Investigations on the electrochemical decomposition of the electrolyte additive vinylene carbonate in Li metal half cells and lithium ion full cells. Journal of Power Sources 2016, 332, 60-71.

(58) Deng, B.; Wang, H.; Ge, W.; Li, X.; Yan, X.; Chen, T.; Qu, M.; Peng, G. Investigating the influence of high temperatures on the cycling stability of a LiNi0.6Co0.2Mn0.2O2 cathode using an innovative electrolyte additive. Electrochimica Acta 2017, 236, 61-71.

(59) Zhao, W.; Zou, L.; Zheng, J.; Jia, H.; Song, J.; Engelhard, M. H.; Wang, C.; Xu, W.; Yang, Y.; Zhang, J. G. Simultaneous stabilization of LiNi0.76 Mn0.14Co0.10 O2 cath- 
ode and lithium metal anode by lithium bis(oxalato)borate as additive. ChemSusChem 2018, 11, 2211-2220.

(60) Piper, D. M.; Evans, T.; Leung, K.; Watkins, T.; Olson, J.; Kim, S. C.; Han, S. S.; Bhat, V.; Oh, K. H.; Buttry, D. A.; Lee, S. H. Stable silicon-ionic liquid interface for next-generation lithium-ion batteries. Nature Communications 2015, 6, 6230.

(61) Zhang, X. Q.; Chen, X.; Hou, L. P.; Li, B. Q.; Cheng, X. B.; Huang, J. Q.; Zhang, Q. Regulating Anions in the Solvation Sheath of Lithium Ions for Stable Lithium Metal Batteries. ACS Energy Letters 2019, 4, 411-416.

(62) Chang, Z. H.; Wang, J. T.; Wu, Z. H.; Gao, M.; Wu, S. J.; Lu, S. G. The Electrochemical Performance of Silicon Nanoparticles in Concentrated Electrolyte. ChemSusChem 2018, 11, 1787-1796.

(63) Wang, R.; Li, X.; Zhang, B.; Wang, Z.; Guo, H. Effect of methylene methanedisulfonate as an additive on the cycling performance of spinel lithium titanate electrode. Journal of Alloys and Compounds 2015, 648, 512-520.

(64) Stokes, K.; Kennedy, T.; Kim, G.-T.; Geaney, H.; Storan, D.; Laffir, F.; Appetecchi, G. B.; Passerini, S.; Ryan, K. Influence of Carbonate-Based Additives on the Electrochemical Performance of Si NW Anodes Cycled in an Ionic Liquid Electrolyte. Nano Letters 2020, 20, 7011-7019.

(65) Evans, T.; Piper, D. M.; Sun, H.; Porcelli, T.; Kim, S. C.; Han, S. S.; Choi, Y. S.; Tian, C.; Nordlund, D.; Doeff, M. M.; Ban, C.; Cho, S. J.; Oh, K. H.; Lee, S. H. In Situ Engineering of the Electrode-Electrolyte Interface for Stabilized Overlithiated Cathodes. Advanced Materials 2017, 29, 1604549.

(66) Lu, Y. C.; Mansour, A. N.; Yabuuchi, N.; Shao-Horn, Y. Probing the origin of enhanced stability of AlPO4 nanoparticle coated LiCoO2 during cycling to high voltages: Combined XRD and XPS studies. Chemistry of Materials 2009, 21, 4408-4424. 
(67) Zhang, J. N.; Li, Q.; Wang, Y.; Zheng, J.; Yu, X.; Li, H. Dynamic evolution of cathode electrolyte interphase (CEI) on high voltage $\mathrm{LiCoO} 2$ cathode and its interaction with Li anode. Energy Storage Materials 2018, 14, 1-7.

(68) Lee, H.; Lim, H. S.; Ren, X.; Yu, L.; Engelhard, M. H.; Han, K. S.; Lee, J.; Kim, H. T.; Xiao, J.; Liu, J.; Xu, W.; Zhang, J. G. Detrimental Effects of Chemical Crossover from the Lithium Anode to Cathode in Rechargeable Lithium Metal Batteries. ACS Energy Letters 2018, 3, 2921-2930.

(69) Liu, B.; Li, Q.; Engelhard, M. H.; He, Y.; Zhang, X.; Mei, D.; Wang, C.; Zhang, J. G.; $\mathrm{Xu}, \mathrm{W}$. Constructing Robust Electrode/Electrolyte Interphases to Enable Wide Temperature Applications of Lithium-Ion Batteries. ACS Applied Materials and Interfaces 2019, 11, 21496-21505.

(70) Kawamura, T.; Okada, S.; Yamaki, J. i. Decomposition reaction of LiPF6-based electrolytes for lithium ion cells. Journal of Power Sources 2006, 156, 547-554.

(71) Yu, Y.; Karayaylali, P.; Katayama, Y.; Giordano, L.; Gauthier, M.; Maglia, F.; Jung, R.; Lund, I.; Shao-Horn, Y. Coupled LiPF6 Decomposition and Carbonate Dehydrogenation Enhanced by Highly Covalent Metal Oxides in High-Energy Li-Ion Batteries. Journal of Physical Chemistry C 2018, 122, 27368-27382.

(72) Ding, X.; Li, Y. X.; Chen, F.; He, X. D.; Yasmin, A.; Hu, Q.; Wen, Z. Y.; Chen, C. H. In situ formation of LiF decoration on a Li-rich material for long-cycle life and superb low-temperature performance. Journal of Materials Chemistry A 2019, 7, 11513-11519.

(73) Yi, T. F.; Mei, J.; Zhu, Y. R. Key strategies for enhancing the cycling stability and rate capacity of LiNi0.5Mn1.5O4 as high-voltage cathode materials for high power lithiumion batteries. Journal of Power Sources 2016, 316, 85-105.

(74) Fischer, F. D.; Svoboda, J. Stresses in hollow nanoparticles. International Journal of Solids and Structures 2010, 47, 2799-2805. 
(75) Shin, H.; Park, J.; Han, S.; Sastry, A. M.; Lu, W. Component-/structure-dependent elasticity of solid electrolyte interphase layer in Li-ion batteries: Experimental and computational studies. Journal of Power Sources 2015, 277, 169-179.

(76) Zheng, J.; Xiao, J.; Yu, X.; Kovarik, L.; Gu, M.; Omenya, F.; Chen, X.; Yang, X. Q.; Liu, J.; Graff, G. L.; Whittingham, M. S.; Zhang, J. G. Enhanced Li + ion transport in LiNi 0.5Mn $1.5 \mathrm{O} 4$ through control of site disorder. Physical Chemistry Chemical Physics 2012, 14, 13515-13521.

(77) Wongittharom, N.; Lee, T. C.; Hung, I. M.; Lee, S. W.; Wang, Y. C.; Chang, J. K. Ionic liquid electrolytes for high-voltage rechargeable Li/LiNi $0.5 \mathrm{Mn} 1.5 \mathrm{O} 4$ cells. Journal of Materials Chemistry A 2014, 2, 3613-3620.

(78) Qiao, Y.; He, Y.; Jiang, K.; Liu, Y.; Li, X.; Jia, M.; Guo, S.; Zhou, H. High-Voltage Li-Ion Full-Cells with Ultralong Term Cycle Life at Elevated Temperature. Advanced Energy Materials 2018, 8, 1802322.

(79) Bak, S. M.; Shadike, Z.; Lin, R.; Yu, X.; Yang, X. Q. In situ/operando synchrotronbased X-ray techniques for lithium-ion battery research. NPG Asia Materials 2018, $10,563-580$.

(80) Boesenberg, U.; Falk, M.; Ryan, C. G.; Kirkham, R.; Menzel, M.; Janek, J.; Fröba, M.; Falkenberg, G.; Fittschen, U. E. Correlation between chemical and morphological heterogeneities in LiNi0.5Mn1.5O4 spinel composite electrodes for lithium-ion batteries determined by micro-X-ray fluorescence analysis. Chemistry of Materials 2015, 27, $2525-2531$.

(81) Robert, R.; Zeng, D.; Lanzirotti, A.; Adamson, P.; Clarke, S. J.; Grey, C. P. Scanning X-ray fluorescence imaging study of lithium insertion into copper based oxysulfides for Li-Ion batteries. Chemistry of Materials 2012, 24, 2684-2691. 
(82) Beckhoff, B.; Kanngießer, B.; Langhoff, N.; Wedell, R.; Wolff, H. Handbook of practical X-ray fluorescence analysis; Springer Science \& Business Media, 2007; pp 335-342. 


\section{Graphical TOC Entry}

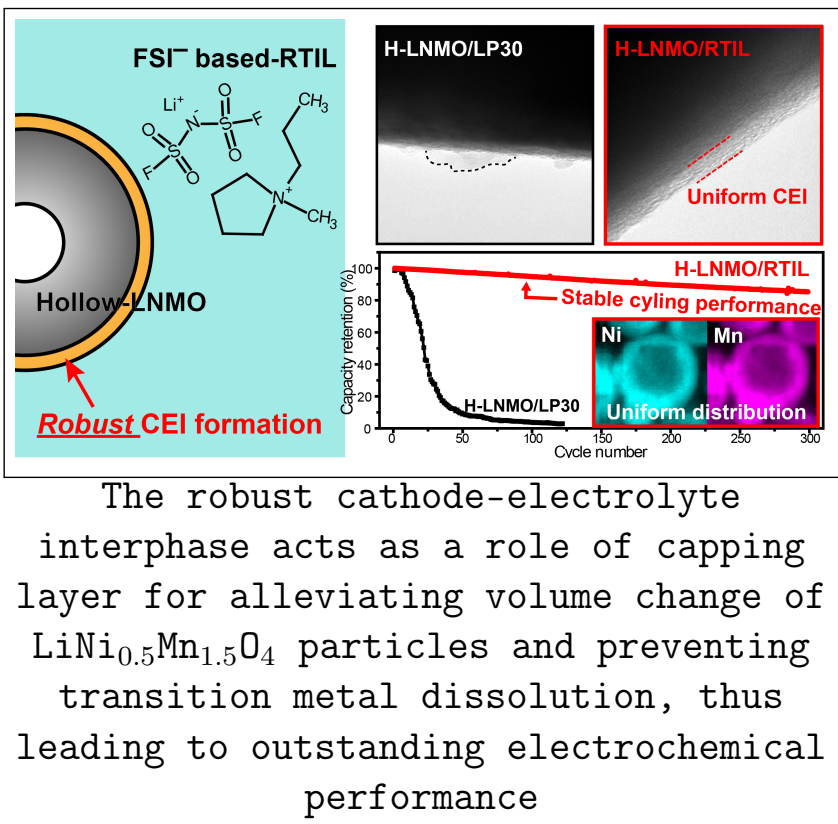

